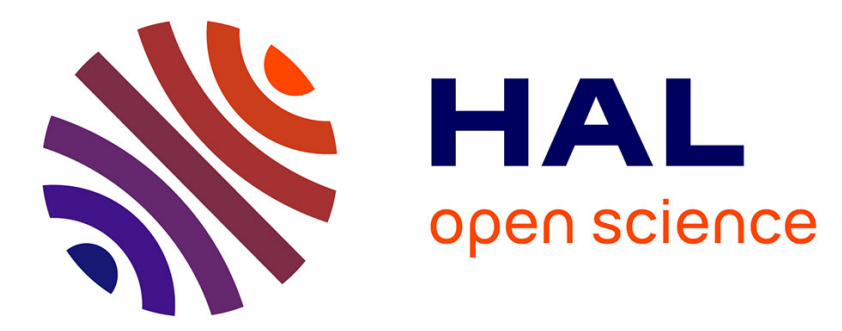

\title{
Is generalisation of uneven-aged management in mountain forests the key to improve biodiversity conservation within forest landscape mosaics?
}

Mathilde Redon, Sandra Luque, Frédéric Gosselin, Thomas Cordonnier

\section{- To cite this version:}

Mathilde Redon, Sandra Luque, Frédéric Gosselin, Thomas Cordonnier. Is generalisation of unevenaged management in mountain forests the key to improve biodiversity conservation within forest landscape mosaics?. Annals of Forest Science, 2014, 71 (7), pp.751 - 760. 10.1007/s13595-014-03717. hal-01102778

\section{HAL Id: hal-01102778 \\ https://hal.science/hal-01102778}

Submitted on 13 Jan 2015

HAL is a multi-disciplinary open access archive for the deposit and dissemination of scientific research documents, whether they are published or not. The documents may come from teaching and research institutions in France or abroad, or from public or private research centers.
L'archive ouverte pluridisciplinaire $\mathbf{H A L}$, est destinée au dépôt et à la diffusion de documents scientifiques de niveau recherche, publiés ou non, émanant des établissements d'enseignement et de recherche français ou étrangers, des laboratoires publics ou privés. 


\title{
Is generalisation of uneven-aged management in mountain forests the key to improve biodiversity conservation within forest landscape mosaics?
}

\author{
Mathilde Redon • Sandra Luque • Frédéric Gosselin • \\ Thomas Cordonnier
}

Received: 27 September 2013 / Accepted: 19 March 2014 / Published online: 17 April 2014

(C) INRA and Springer-Verlag France 2014

\begin{abstract}
- Context Uneven-aged management systems based on selection silviculture have become popular in European mountain forests and progressively replace other silvicultural practices. In time, this trend could lead to a homogenisation of the forest mosaic with consequences on structural indices recognised as beneficial to forest biodiversity.

- Aims This study was conducted to investigate the potential effects of a generalisation of the selection silvicultural system on structural diversity in the forest landscape with consequences for forest biodiversity conservation.
\end{abstract}

\section{Handling Editor: Laurent Bergès}

Contributions of the co-authors Mathilde Redon: selecting structural indices, designing the experiment and doing field work, ranking of stand types according to the results of statistical analysis and writing the paper. Sandra Luque: supervising the work and revising the paper.

Thomas Cordonnier: supervising the research project, designing the experiment and doing field work, performing the simulation study and writing the paper.

Frédéric Gosselin: performing statistical analyses and writing corresponding parts; revising the paper.

Electronic supplementary material The online version of this article (doi:10.1007/s13595-014-0371-7) contains supplementary material, which is available to authorized users.

M. Redon $\cdot \mathrm{S}$. Luque $\cdot$ T. Cordonnier $(\bowtie)$

Irstea, UR EMGR, 2 rue de la papeterie-BP 76,

F-38402 Saint-Martin-d'Hères, France

e-mail: thomas.cordonnier@irstea.fr

M. Redon

e-mail: mathilde.redon@gmail.com

\section{S. Luque}

Department of Geography and Sustainable Development,

University of St Andrews, St. Andrews, Scotland, UK

F. Gosselin

Irstea, UR EFNO, Centre de Nogent-sur-Vernisson,

45290 Nogent-Sur-Vernisson, France
- Methods We compared four structural indices (tree species richness, diameter heterogeneity, deadwood volume and basal area of mature trees) in five different stand types typical of the northern French Alps, using forest plot data in the Vercors mountain range. Through virtual landscape simulations, we then calculated predicted mean proportions of stand types under two different conservation strategies: (i) maximising mean index values at the landscape level and (ii) maximising the number of plots in the landscape with index values above given thresholds.

- Results Multi-staged forests did not maximise all indices, the best solution being to combine the five stand types in uneven proportions to improve biodiversity conservation.

- Conclusion The expansion of selection silviculture in European heterogeneous forest landscapes could enhance biodiversity conservation if other stand types with complementary structural characteristics are maintained.

Keywords Uneven-aged management $\cdot$ Selection silviculture $\cdot$ Biodiversity indicators $\cdot$ Stand structural diversity $\cdot$ Mountain forests $\cdot$ Landscape homogenisation

\section{Introduction}

The importance of including biodiversity protection in forest management has now been recognised in international political processes (MCPFE 2003). In an attempt to reach this objective, there is today a global trend in temperate and boreal forests to shift management strategies towards more ecological-based silvicultural systems such as continuous cover systems (O'Hara 2009).

In some European mountain forests, for instance, group or single-tree selection silvicultural systems have been favoured (Bagnaresi et al. 2002) as they provide several advantages compared to other traditional silvicultural practices: (i) they increase stand structural diversity, which plays a key role in 
maintaining forest biodiversity (McMullin et al. 2010), (ii) they help to maintain a constant canopy cover and thus improve protection from natural hazards (Cordonnier et al. 2008) and (iii) they enhance the visual amenity of the managed forests, making them more attractive for local tourism and related activities.

Although the application of the selection silvicultural systems on large forest areas can potentially help to preserve some forest biodiversity, it can conversely lead to a strong homogenisation of stand structures in forest landscapes (Decocq et al. 2004; Angers et al. 2005). At the landscape level, spatial heterogeneity of habitats and structural characteristics are known to favour forest biodiversity (Poirazidis et al. 2010), as a diversity of resources and habitats allows specialist species, which are linked to each of these habitats, and generalist species, which use several habitats, to coexist (Fahrig et al. 2011). Several authors have shown that this homogenisation of forest structural attributes over an entire landscape can reduce biodiversity (Beese and Bryant 1999; Werner and Raffa 2000).

However, in the case of the generalisation of multi-staged stand silviculture, the possible adverse consequences of largescale homogenisation on the forest mosaic characteristics beneficial to biodiversity are not clear. Although favourable to biodiversity in several aspects, such a generalisation could lead to a lack of some important forest landscape features such as very large gaps, large young stands or monospecific and even-aged stands, which are also known to be beneficial to some forest-dwelling species (Bouget and Duelli 2004; Ares et al. 2009). Very few studies address this issue within the framework of biodiversity conservation in managed forests (e.g. Angers et al. 2005).

In this article, we try to shed some light on the potential effects of a generalisation of multi-staged stands promoted by selection silviculture on the availability of structural characteristics that are important for the maintenance of forest biodiversity. We focused our analysis on five stand types related to traditional silvicultural systems: multi-staged, two-staged, uniform, coppice and coppice with standards (see Matthews 1991). The study took place in the public forests of the Vercors mountain range in the French Alps. In this area, physical characteristics such as topography imprint a natural heterogeneity to the landscape matrix. The dominant landscape in this region of the Alps is a patchwork of different forest blocks resulting from heterogeneous physical constraints and from a management history that until recently was driven by a high diversification of silvicultural systems. Today, almost all forests in this area are progressively converted into multi-staged forests through the application of group or single-tree selection silviculture (see guidelines in Gauquelin and Courbaud 2006). This geographic area therefore provides a good opportunity to analyse the potential effects of a transition from a complex mosaic of stand types towards the generalisation of a single silvicultural treatment on forest features that are considered as important for forest biodiversity.

In this study, our objective was to see if, at the forest landscape level, some combination of the five different stand types considered would result in more structural characteristics favourable to the conservation of biodiversity than the multi-staged stand type alone. Two different approaches were implemented. First, we quantified differences between stand types in terms of four structural indices that have direct links to the conservation of a wide range of forest-dwelling species: tree species richness, diameter heterogeneity, deadwood volume and basal area of mature trees. This quantification allowed us to rank the five stand types based on the distribution of their index values. Second, this ranking was used to see if several stand types are needed to maximise the four indices in a virtual forest landscape mosaic. We carried out simulations of virtual landscapes in order to determine what proportions of stand types maximised the four indices at the landscape level under two different conservation strategies: (i) maximising mean index values at the landscape level and (ii) maximising the number of plots in the landscape with index values above given thresholds. As generally expected, we assumed that multi-staged forests would have the highest values for the four indices in most cases and thus that a landscape exclusively composed of this stand type would be the best way to promote biodiversity conservation under the two conservation strategies. A comparison of predicted proportions with real proportions of stand types within the study area helps to provide management recommendations to enhance forest biodiversity conservation.

\section{Material and methods}

\subsection{Study area and stand types}

The Vercors mountain forests cover nearly 139,000 ha in the south-western part of the Alpine Arch (pre-Alps region, Fig. 1). Fifty percent of these forests are divided into numerous small privately owned areas with a high diversity of management practices. The other half is all public forests, managed by the National Forest Office (NFO). NFO applies conservation guidelines defined at the regional level favouring homogeneous conservation practices among forest areas and among stand types. We only considered public forests in this study as homogeneous spatial information on stand characteristics was not available for private forests.

The studied forests have a relatively simple tree species composition based mainly on three timber tree species: European beech (Fagus sylvatica), Norway spruce (Picea abies) and silver fir (Abies alba), accompanied by several secondary broad-leaved species such as sycamore (Acer pseudoplatanus) and Italian maple (Acer opalus), common whitebeam (Sorbus 


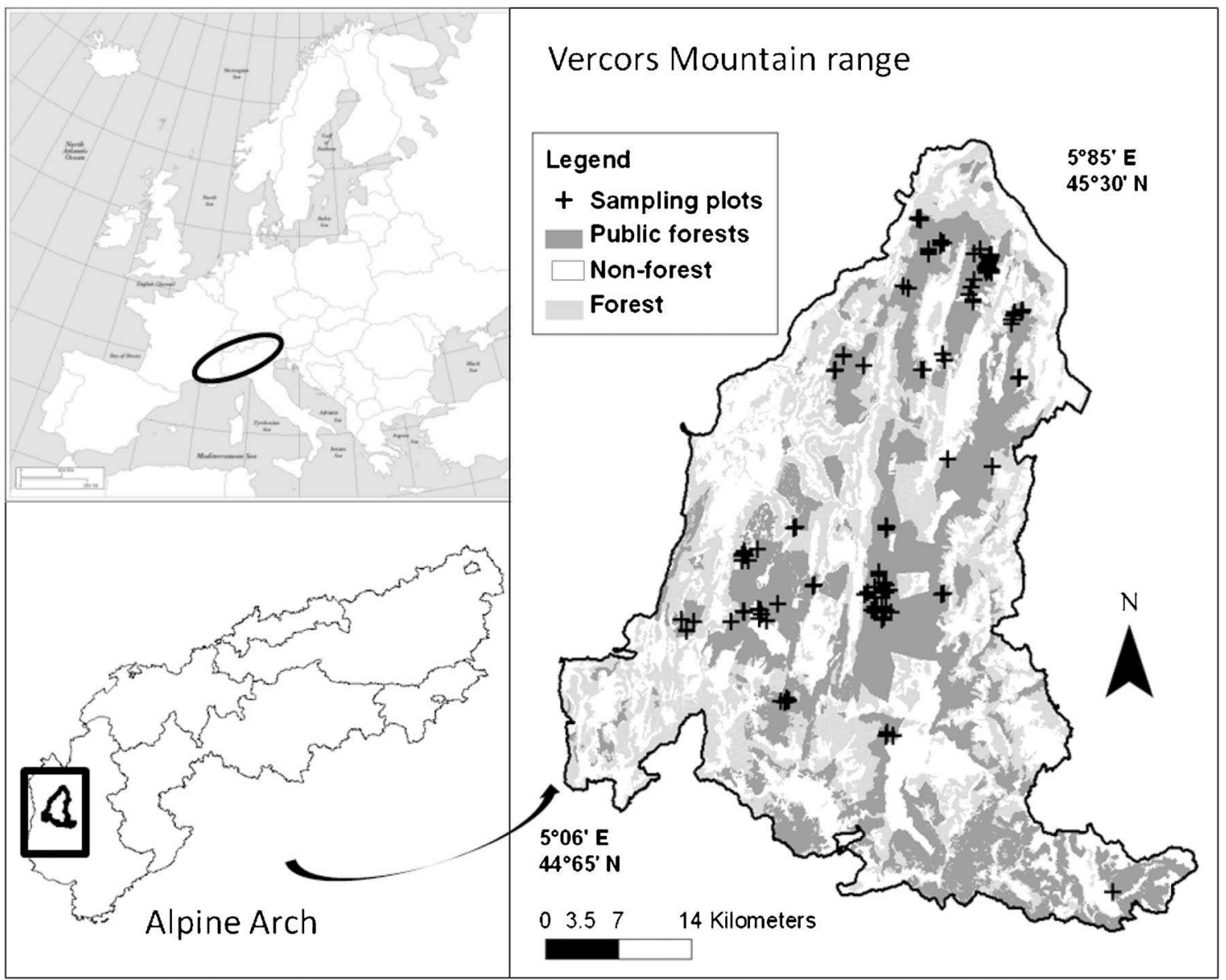

Fig. 1 Study area location

aria), European mountain ash (Sorbus aucuparia) and mountain pine (Pinus uncinata) at high elevation $(\geq 1,500 \mathrm{~m})$. These forests have been mostly shaped by the heterogeneous mountain topography and a long history of human interventions. During the eighteenth century, almost all forests were intensively exploited for firewood, which favoured beech coppices. Since the early twentieth century, they have been progressively converted into mixed high forests, sometimes by plantation of local coniferous species but often by natural recolonisation of abandoned pastoral or cultivated lands. For these high forests, uneven-aged management was predominant, but some areas were managed under the shelterwood or uniform system with a typical thinning cycle of 12 years.

We distinguished five main stand types according to the number of distinct canopy strata: (1) multi-staged stands (MS - at least three strata of high forest) that directly result from single-tree or group selection silviculture, (2) two-staged stands (TS - two dominant strata of high forest), (3) uniform stands (UN-one dominant stratum) that were managed as shelterwood or uniform systems, (4) coppice with standards (CS - one stratum of coppice and one or more strata of high forest) that resulted from the progressive retention of standards (usually conifers) inside coppices which have been either selection cut or clear cut and (5) simple coppices that were clear cut (CO). Because of the conversion process towards uneven-aged forests, young stands created by final cuts in even-aged systems were poorly represented in the study area, and the five stand types considered were mature forests (quadratic mean diameter $>20 \mathrm{~cm}$ ).

\subsection{Sampling design}

In the study area, $58020-\mathrm{m}$ radius plots were set up by the NFO between 1995 and 2010 to gather dendrometric data from living trees and deadwood. These plots were mainly located in protected areas (recently managed, still managed or unmanaged), with a highly uneven spatial distribution. We first selected 62 of these 580 plots. The selection was based on several criteria: (i) stand type distribution, to represent as much as possible the five studied stand types; (ii) abiotic conditions, to limit oversampling coppice-like stands on poor soils at low elevations and high-forest-like stands on deep soils at intermediate elevations and (iii) management practices, to avoid selecting plots in long-time unmanaged forests or in very specific stand types (e.g. opened forests). 
We then complemented this first dataset by measuring 64 additional plots during spring and summer 2010. Our aims were to obtain a minimum of 20 plots per stand type and to avoid a highly unbalanced plot number among stand types. Stand types and the location of the additional sampling points were determined with a recent map of the Vercors mountain range forest structures. In all, 126 plots were used for the study: 28 plots for MS, 19 plots for TS, 29 plots for UN, 22 plots for $\mathrm{CO}$ and 28 plots for CS.

In order to combine our field data with existing data sets, we used the same sampling method as NFO to measure both living and dead trees in the 64 additional plots. This method was simplified from Bruciamacchie (2005) that was based on tree dimensions, species composition and micro-habitat inventory. The field sampling method consisted of setting up different nested plot types where living trees, standing dead trees, fallen dead trees and stumps were measured depending on their size. In the field, we used a GPS to locate each plot and confirmed stand type by observations of stand structure. Living trees, standing dead trees and stumps with a diameter (at breast height for living and standing dead trees) between 7.5 and $30 \mathrm{~cm}$ were measured in fixed-area plots with a $10-\mathrm{m}$ radius. Coarse woody debris, large standing dead trees and stumps (diameter $\geq 30 \mathrm{~cm}$ ) were sampled within fixed-area plots with a $20-\mathrm{m}$ radius. Living trees with a diameter $\geq 30 \mathrm{~cm}$ were sampled with a fixed-angle sampling method. We used an angle of 3/100 which meant that a tree was measured if its distance to the plot centre in metres was equal to or lower than $1 / 3$ of its diameter in centimetres. Finally, a line intersect sampling method was used for fine woody debris $(7.5 \leq$ diameter $<30 \mathrm{~cm}$ ). Three transects $20 \mathrm{~m}$ long radiating out from the plot centre were set up on the ground. The direction of the first transect was chosen randomly, and the two others were at an angle of $120^{\circ}$ and $240^{\circ}$ to the first.

For each piece of fine woody debris intersected by a transect, we measured the diameter at the transect intersection and the angle of the pieces from the ground. For all living trees and standing dead trees, we took two perpendicular measurements of the diameter at breast height. We also recorded tree species for all measured living trees and height for standing dead trees. For coarse woody debris, we measured the length of each piece, one median diameter when the piece was less than $5 \mathrm{~m}$ long and three diameters (median and at the two ends) for pieces more than $5 \mathrm{~m}$ long. When a woody debris was only partly included in the $20-\mathrm{m}$ radius plot, we only considered the part of the woody debris that lay within the plot. Finally, for stumps, we measured two perpendicular diameters and both uphill and downhill heights.

\subsection{Structural indices}

We used four indices to describe stand structures at the plot level: tree species richness, diameter heterogeneity, deadwood volume and basal area of mature trees, representing widely used descriptors of forest structural heterogeneity that are considered as surrogates for forest biodiversity (Appendix S1). They are also influenced by silviculture through production and conservation practices (e.g. tree removal, tree and deadwood retention). We tested correlations among the different indices with a Spearman rank test on the entire dataset and on each stand type independently. All correlation coefficients were lower than 0.50 , showing limited redundancy in our case study. The four indices were calculated as follows:

- Tree species richness (SR) was quantified as the number of species recorded among trees measured in a plot.

- Diameter heterogeneity was quantified as the coefficient of variation (CVD) of the diameter at breast height (dbh):

$$
\mathrm{CVD}=100^{*} \mathrm{SD}_{\mathrm{dbh}} / \mu_{\mathrm{dbh}}
$$

where $\mathrm{SD}_{\mathrm{dbh}}$ was the standard deviation of the dbh distribution and $\mu_{\mathrm{dbh}}$ the mean $\mathrm{dbh}$. It is null when only one tree is measured or when all trees have the same diameter and increases with the increasing dispersion of diameter values around their mean.

- Deadwood volume (DWV, $\mathrm{m}^{3} \mathrm{ha}^{-1}$ ) reflected the quantity of deadwood material whatever its origin. It represents the total volume of standing dead trees, coarse (diameter $\geq 30 \mathrm{~cm}$ ) and fine (diameter $<30 \mathrm{~cm}$ ) woody debris and stumps.

- Basal area of mature trees (MTBA, $\mathrm{m}^{2} \mathrm{ha}^{-1}$ ) was quantified as the total basal area of trees with a dbh superior to $45 \mathrm{~cm}$. This value represented a reasonable threshold given the mean productivity of the forests in the study area and also corresponded to a threshold above which the expected number of microhabitats per tree reached a plateau (Vuidot et al. 2011).

We assumed that the higher the values of these indices at the plot level, the better the local conditions for biodiversity conservation. The suitability of conditions for biodiversity was then assessed at two levels: (i) the stand level for stand type ranking and comparisons (mean and standard error values of indices per stand type) and (ii) the forest landscape level for virtual landscape simulations.

\subsection{Stand type ranking and comparison}

Our objective was to rank quantitatively the five stand types according to their structural diversity. We therefore discarded non-parametric statistical methods that concentrate on statistical significance and do not allow the estimation of the magnitude of the effect (Harrell 2001). A further matter for our statistical analyses was to find a statistical method with adequate probability distributions to represent the nature of 
our data. Since the original scale of the structural data we used was the target of our analyses, we did not want to transform the data-for example logarithmically (McArdle and Anderson 2004). Instead, we preferred a two-stage bootstrapping methodology, like the one implemented by Fox (2002), which allows the estimation of the magnitude of the effect and is a priori less sensitive to distributional issues (Fox 2002; but see McArdle and Anderson 2004).

First, for each structural index, we used an ordinary nonparametric bootstrap to estimate the difference between mean values for each combination of stand types. The mean values for each stand type were estimated from a robust linear model. To avoid potential confusing effects of abiotic factors on stand structural attributes (e.g. higher species richness in coppices due to lower elevations), we incorporated elevation and slope variables as covariates in these models. Second, the bootstrap confidence interval of each bootstrapped difference was calculated through a bias-corrected accelerated percentile intervals bootstrap procedure (Di Ciccio and Romano 1988; function boot.ci in R). This calculation was done for each percentile level between 0.001 and 0.999 by increments of 0.001 . We then kept, for each two-by-two difference, the lowest percentile level for which the 0 value was not in the confidence interval. Third, the significance (alpha $=0.05$ ) of the resulting multiple $p$ values (one per difference of stand types) was established for each structural index using the Holm-Bonferroni correction for multiple hypotheses (Holm 1979).

Fourth, for each structural index, we ranked the five stand types according to their ordered statistical differences. Statistical differences were represented by combinations of letters: "a", "ab", "b", "abc", "bc", "c" and "d", where "a" was given to the stand type (or stand types) with the highest index value (Fig. 2). Double letters, for example "ab", meant that the stand type was not significantly different from the stand types with letters "a" and "b" for the index considered. In order to establish if a stand type could combine the highest values for all indices, we compared the final statistical ranks of stand types for the four indices.

\subsection{Analysing the complementarities among stand types at the landscape level: a simulation study}

We performed a simulation study, in order to determine what combination and proportion of the five stand types allowed maximising the four indices at the landscape level. Two
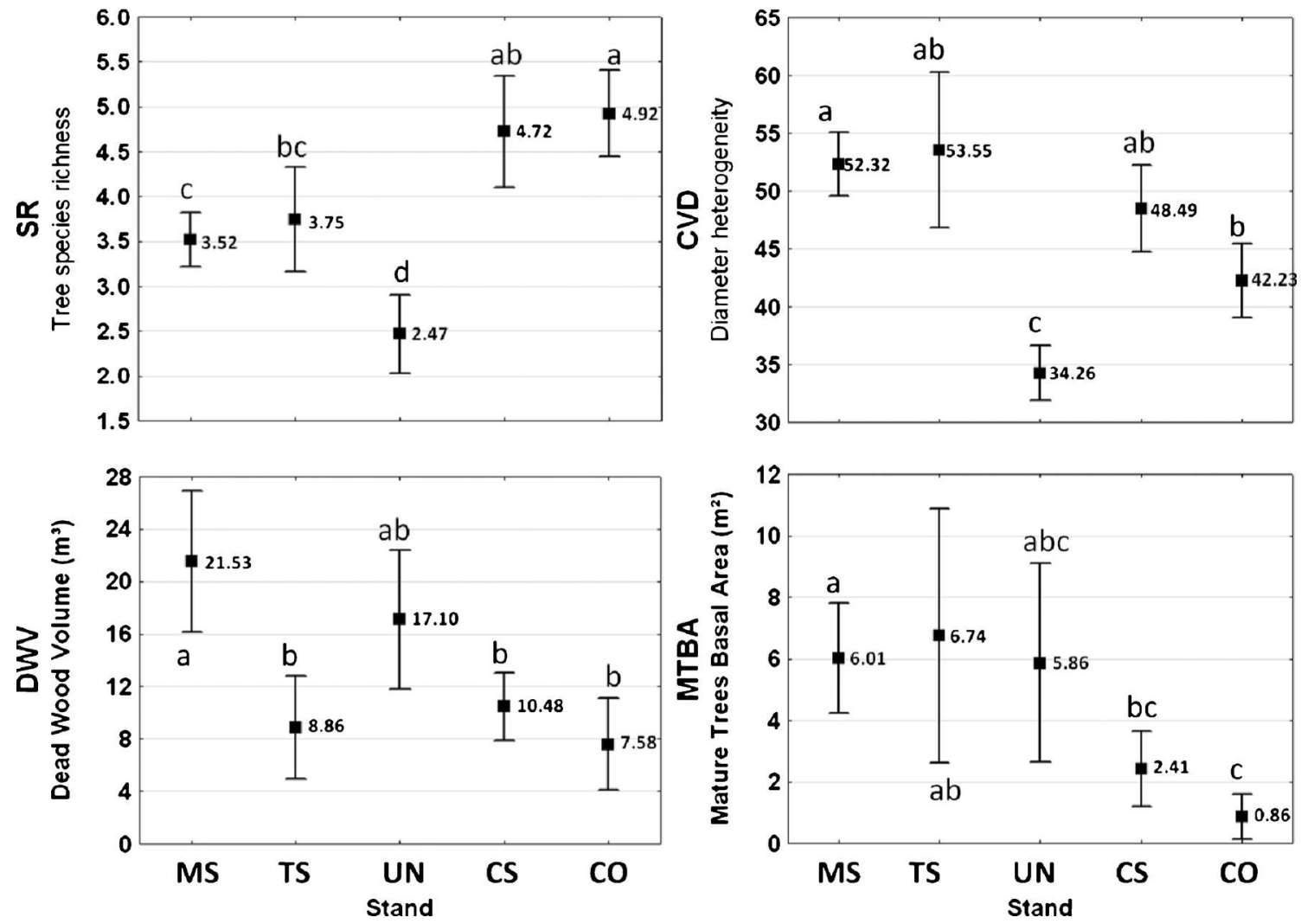

Fig. 2 Mean values and $95 \%$ confidence intervals for the four indices of stand structural diversity, tree species richness $(S R)$, diameter heterogeneity $(C V D)$, deadwood volume $(D W V)$ and basal area of mature trees $(M T B A)$, by stand types. Values were corrected for a slope of $30 \%$ and an elevation of 1,300 m. MS =multi-staged stands ( 28 plots); $T S=$ two-staged

stands (19 plots); $U N=$ uniform stands (29 plots); $C S=$ coppices with standards ( 28 plots); $C O=$ simple coppices ( 22 plots). Letters represent significant differences between stands (elevation and slope effects removed) according to the Holm-Bonferroni post hoc test for multiple comparisons 
different strategies were considered: the first one was based on the mean performance of the forest landscape according to the four indices (ML for mean landscape strategy); the second one was based on the mean proportion of plots that had indices above a threshold value at the plot level (LT for landscape threshold strategy). This double strategy was related to the fact that while species richness of some taxonomic groups might respond to mean landscape features, some species-especially rare species - might require high levels of limiting resources at the local scale (e.g. an example in Økland et al. 1996).

A simulation was generated by varying the proportion of stand types by steps of 0.05 , with the sum of stand proportions equalling 1. Hence, one simulation led to 194,481 virtual landscapes, corresponding to the total number of possible vectors of stand type proportions. For each virtual landscape of one simulation, the following steps were done:

(i) Determining the number of plots per stand type (the number of plots for a given stand type was proportional to this stand type's occurrence within the virtual landscape; the total number of plots for a virtual landscape was set to 20 , a value close to the mean number of plots per stand type in our dataset)

(ii) Randomly selecting plots with replacement in stand types

(iii) For the ML strategy, calculating mean values of structural indices over the whole simulated landscape and calculating the resulting score for the landscape (see score calculation details below)

(iv) For the LT strategy, for each structural index in the simulated landscape, calculating the number of plots in the landscape where the index value is greater than a given threshold value

To control for abiotic factors in the calculation of the landscape scores, we used the mean coefficient estimates of elevation and slope effects obtained in the two-stage bootstrapping procedure (see Section 2.4). For all plots, we adjusted indices by setting the elevation to $1,300 \mathrm{~m}$ and slope to $30 \%$ which were close to mean plot values.

Threshold values were defined according to reasonable targets of forest management for the region studied and also according to the distribution of values recorded in the study area, taking into account results from several other European studies (Økland et al. 1996; Penttilä et al. 2004). Threshold values were 4 for species richness, $50 \%$ for diameter coefficient of variation, $20 \mathrm{~m}^{3} \mathrm{ha}^{-1}$ for deadwood volume and $8 \mathrm{~m}^{2} \mathrm{ha}^{-1}$ for mature tree basal area. The score was defined as follows:

score $=\sum_{i=1}^{4} \frac{\mu_{i}}{q_{0.9}\left(x_{i}\right)}$ with $\mu_{i}$ being the mean value of the structural index $i$ and $q_{0.9}\left(x_{i}\right)$ the 0.9 quantile value of the structural index $i$ among all plots. We used the 0.9 quantile instead of the maximum value to avoid overweighting of indices displaying right skewed distributions (i.e. basal area of mature trees). This scoring system allows weighting each index according to its importance for biodiversity. However, in our study area, there was no available information to compare the importance of the indices, and we therefore chose not to weight them.

At the end of the simulation, we retained the virtual landscape with the best score for the ML strategy and the virtual landscape with the highest proportion of plots with indices above the chosen thresholds for the LT strategy.

One hundred simulations were performed leading to 100 high-scoring landscapes for each conservation strategy. For each conservation strategy, we then calculated the mean and standard error of stand type proportions (i.e. number of plots/total number of plots) obtained in these high-scoring landscapes. Finally, we compared the results obtained with the real proportions of stand types in the public forests of the Vercors mountain range, which were defined according to the same map of forest structures as that used for the sampling design.

\section{Results}

\subsection{Ranking of stand types}

Structural diversity differed both qualitatively and quantitatively among stand types. No stand type showed systematically high or low values for all four indices, which were differently ranked from one stand type to another (Fig. 2). Table 1 summarises index levels by stand types. Based on the four indices, MS were the most structurally diverse (majority of indices in categories "a" or "ab"). Next, we found TS, CS and, finally, $\mathrm{UN}$ and $\mathrm{CO}$ as the least diverse stand types (majority of indices in the categories "b", "bc", "c" and "d") (Table 1).

\subsection{Complementarities among stand types at the landscape} level

The simulation study confirmed that a combination of several stand types is needed to maximise the four index values at the landscape level (Fig. 3). As expected from their high structural diversity, MS and TS appeared dominant in simulated landscapes, occupying up to $82 \%$ (61\% for MS and $21 \%$ for TS) of the area for the ML strategy and $68 \%$ (44\% for MS and $24 \%$ for TS) of the area for the LT strategy. These values contrasted with the one of $44 \%$ (34\% for MS and $10 \%$ for TS) obtained in 
Table 1 Ranking of stand types according to significant differences in index values. Letters represent significant statistical differences between the stand types for a given index, where "a" was given to the stand type (or stand types) with the highest value. Double letters, for example "ab", meant that the stand type was not significantly different from the stand types with letters "a" and "b" for the index under consideration. The cases with highest index values are represented in italics

\begin{tabular}{|c|c|c|c|c|}
\hline \multirow[t]{2}{*}{ Stand type } & \multicolumn{4}{|c|}{ Forest structural diversity indices } \\
\hline & $\begin{array}{l}\text { Tree species richness } \\
\text { SR }\end{array}$ & $\begin{array}{l}\text { Diameter heterogeneity } \\
\text { CVD }\end{array}$ & $\begin{array}{l}\text { Deadwood volume } \\
\text { DWV }\end{array}$ & $\begin{array}{l}\text { Mature trees basal area } \\
\text { MTBA }\end{array}$ \\
\hline Multi-staged (MS) & $\mathrm{c}$ & $a$ & $a$ & $a$ \\
\hline Two-staged (TS) & $\mathrm{bc}$ & $a b$ & $\mathrm{~b}$ & $a b$ \\
\hline Uniform (UN) & $\mathrm{d}$ & $\mathrm{c}$ & $a b$ & $a b c$ \\
\hline Coppice with standards (CS) & $a b$ & $a b$ & $\mathrm{~b}$ & $\mathrm{bc}$ \\
\hline Coppice (CO) & $a$ & $\mathrm{~b}$ & $\mathrm{~b}$ & c \\
\hline
\end{tabular}

the real landscape situation. The three other stand types were predicted to have an area between $3 \%(\mathrm{CO})$ and $8 \%$ (UN) of the landscape for the ML strategy and between $7 \%(\mathrm{CO})$ and $14 \%(\mathrm{CS})$ for the LT strategy.

The stand type proportions changed according to the strategy adopted to evaluate simulated landscapes. For the LT strategy, UN showed higher proportions than CS. It was the opposite for the ML strategy. The simulated landscapes appeared very different from the real landscape, with lower proportions of $\mathrm{CO}$ and $\mathrm{UN}$ in the simulated landscape.

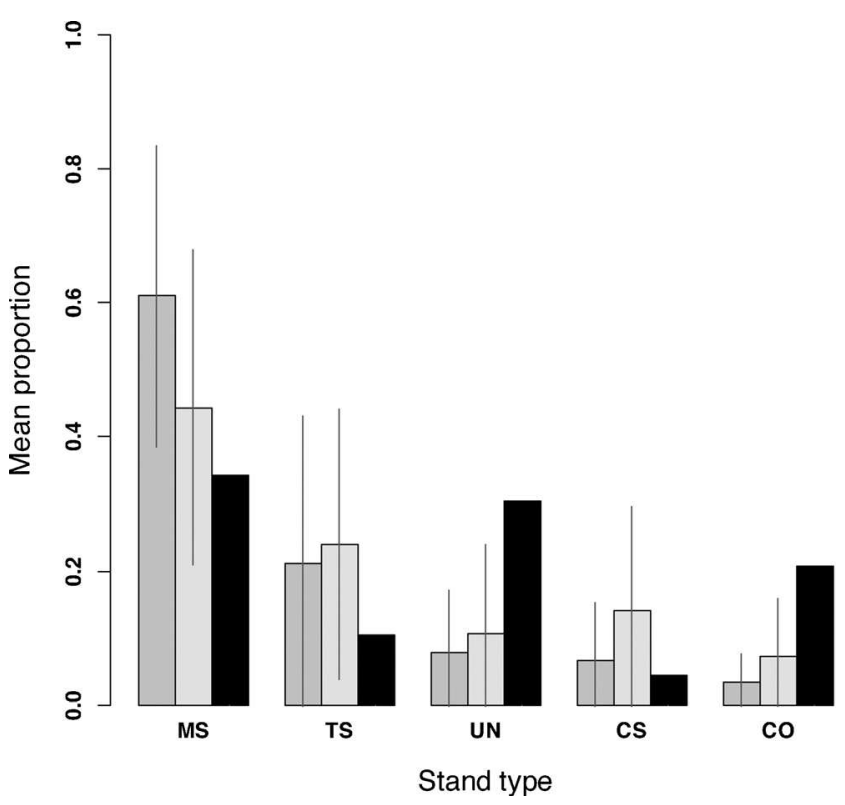

Fig. 3 Mean proportions and associated standard deviations (100 simulations) of each stand type in virtual landscapes for two different strategies: maximising the score at the landscape level (dark grey, mean landscape strategy) and maximising the number of plots with the four indices above a given threshold value in the landscape (light grey, landscape threshold strategy). In black, the real values for public forests in the Vercors mountain range. $M S=$ multi-staged stands; $T S=$ two-staged stands; $U N=$ uniform stands; $C S=$ coppices with standards; $C O=$ simple coppices

\section{Discussion}

The generalisation of selection silvicultural systems in European forests is considered to be a good alternative way to enhance local forest biodiversity. However, increasing evidence suggests that it could also lead to a strong homogenisation of some forest structural characteristics at the forest landscape level, with possible adverse consequences for related forest-dwelling species. We therefore aimed to establish if, at the forest landscape level, a combination of different stand types among the five types considered brought more favourable structural characteristics to biodiversity conservation than the multi-staged stand type alone. We hope that the findings would help to provide paths for further investigation of the complex issue of an ecological-oriented forest management.

4.1 Are several stand types necessary to improve structural diversity at the landscape level?

As generally expected, multi-staged forests appeared to be the most structurally diverse. Nevertheless, they were very close to two-staged forests, and they did not maximise all four indices, especially tree species richness. Our results thus did not support the generally assumed hypothesis that multistaged forests represent the best way to obtain high structural diversity at the landscape level. In our study area, multi-staged forests are mainly managed under single-tree or small group selection systems. In temperate forests, this type of management leaves only very small canopy openings, which actually favours dominant shade-tolerant tree species such as silver fir and European beech. Hence, it seems that even though multistaged forests appear to be a good compromise for improving forest structural diversity at the local scale, they still lack key features to enhance diversification at the landscape level (Uotila and Kouki 2005; Ares et al. 2009). As a corollary, several forest stand types should be maintained to increase the chance of getting high values of different structural indices 
related to biodiversity conservation in the forest landscape. To our knowledge, this study is the first attempt to evaluate this hypothesis within the context of heterogeneous mountain forest landscapes, although such a hypothesis has already been investigated in other contexts (Hansen et al. 1995; Decocq et al. 2004). Our results based on structural indices are in line with those of previous studies showing that a diversity of stand types can shelter more species, in particular in the case of understory vegetation, small mammals, ground-occurring beetles and wintering birds (Haveri and Carey 2000; Werner and Raffa 2000; Carey 2001; Chávez and Macdonald 2010). As an example, it has been found that shelterwood systems (the same system as for UN and TS in our study area) and coppices with standards seem to contain higher understory plant diversity than old-growth forests and single-tree selection systems (Beese and Bryant 1999; Battles et al. 2001). Conversely, birds and plants typical of late successional stand types seem to prefer multi-staged, selectively harvested forests (Willson 1974).

Our semi-quantitative analysis showed complementarities between the structural attributes of the five stand types that could be exploited to improve biodiversity conservation in complex mountain forest areas. MS, TS and, to a lesser extent, CS provided high diameter heterogeneity through their multiaged composition. CS and CO had the highest tree species richness due to the presence of many light-demanding broadleaved species such as common whitebeam and European mountain ash. As expected from their diameter composition, the other three stand types (i.e. MS, TS and UN) contained high densities of mature trees, with TS having the highest value for this index. Finally, MS and UN presented the highest deadwood volume. Surprisingly, TS had a lower value than MS and UN for deadwood volume and did not differ significantly from CO and CS. Historically, TS and UN were managed in a similar way, but today, TS are managed in selection silvicultural systems like MS. We therefore expected a deadwood volume closer to those of these two other stand types. This result could be explained by the particular structure of the TS with a long history of sparse dominant stratum combined with low basal area of large-diameter trees resulting in a denser sub-stratum of smaller trees. This particular structural characteristic has certainly resulted in lower harvest intensity in TS (as compared to MS, UN and CS) leading to a lower volume of exploitation remnants. Furthermore, the long-term low density in the dominant layer may have implied that tree mortality due to competition was naturally reduced, which also contributed to a lower deadwood volume.

4.2 What proportion of stand types allows maximising forest landscape structural diversity?

Our analyses showed that two combinations of stand type proportions could be considered to maximise structural diversity in the forest landscape. These two combinations contained high proportions of MS and TS (respectively 56 and $26 \%$ for the ML strategy and 48 and $23 \%$ for the LT strategy) and low proportions of CO (respectively 4 and $6 \%$ ). They are differentiated by the proportions of UN and CS, which varied according to the strategy adopted. If the aim is to maximise mean forest landscape structural diversity (ML strategy), the proportion of UN would be higher than the proportion of CS (predicted suitable values were $9 \%$ for $\mathrm{UN}$ and $6 \%$ for CS). On the contrary, if the aim is to maximise the number of plots with the indices above a given threshold in the landscape (LT strategy), the proportion of CS should be higher than the proportion of UN (respective predicted values 13 and $11 \%$ ).

The real proportions of UN and CO appeared far higher than values predicted in the two strategies to maximise forest structural diversity, whereas the proportions of MS, TS and CS were lower. In its present state, the forest landscape of the study area therefore does not maximise forest structural diversity as defined by our four indices and according to the two strategies considered. The simulation study showed that an increase in MS, TS and CS and a decrease in UN and CO would be necessary to reach optimal predicted proportions. Today, UN, TS and CS are converted into MS, and CO is progressively replaced by UN and MS. In the medium term, we should therefore expect a decrease in TS and coppice-like (CO and CS) stands with, at the same time, an increase in MS. For CO and MS, this dynamic seems to go in the correct direction for reaching optimal stand type proportions as predicted by the two strategies. However, TS and CS should be expanded to reach the predicted proportions instead of being converted into multi-staged stands. The case of UN seemed to be more complicated in terms of structural dynamics. In fact, due to the conversion of $\mathrm{CO}$ into $\mathrm{UN}$, this stand type is expected to increase in some places while still decrease when converted into MS. Because of this complex dynamics, future proportions of UN stands appear to be quite difficult to predict. Nevertheless, UN stands are currently better represented than $\mathrm{CO}$ stands, which are, in addition, converted into two different stand types (UN and MS). In the study area, the proportion of UN stands would therefore certainly decrease more rapidly in the near future due to conversion into MS stand types, thus going in the right direction to reach optimal predicted proportions.

It is important to note that the proportions of stand types in our virtual landscapes may depend on the set of stand types included in the analyses. For example, we only considered mature stand types (mean quadratic diameter $>20 \mathrm{~cm}$ ), leaving apart young uniform forests because of their scarcity in the study area. These forests can present particular structural characteristics, such as very dense patches of young trees or the presence of numerous pieces of fine woody debris due to natural mortality by competition. Young phases of uniform 
stands could contribute to improve the interest of this management system. A way to circumvent this issue would be to integrate time scale by defining stands according to development or dynamic stages (see Spies and Turner 1999). However, the complexity of silvicultural systems and the multiplicity of historical pathways in mountain areas make the exercise highly difficult. Another promising approach lies within the use of indices that take into account the harvest regimes applied in stands. For instance, Schall and Ammer (2013) have developed indices that allow quantifying management intensity in central European forests. These indices appear efficient in segregating managed and unmanaged stands as well as segregating management systems. However, we still need to provide further insights to understand whether or not these indices influence forest biodiversity. At least, it necessitates additional information such as stand age and maximum basal area which are not always available.

In all, our results suggested that the present management trend in European mountain forests that consisted in expanding selection silvicultural systems may, as expected, enhance forest structural diversity at the landscape level. Nevertheless, other silvicultural systems leading to stand types with higher tree species richness (i.e. coppice with standards or simple coppices) should also be maintained in order to favour forest biodiversity conservation at the landscape level. The respective proportions of stand types within public forests of the Vercors mountain range showed that these typical heterogeneous European forests are at present not at risk of becoming negatively affected by the generalisation of MS.

\subsection{A need to explore the magnitude of the effect of stand structural characteristics on forest biodiversity}

The analyses presented in this study represent a rather new way to consider biodiversity in forest management planning at the landscape level. Nevertheless, the use of indirect biodiversity indicators based on the quantification of stand structural diversity still raises questions about the characteristics of the relationships between these index values and biodiversity. Numerous studies have developed indices describing structural diversity, assuming a positive relationship between stand structural physiognomy and forest biodiversity (McElhinny et al. 2005). Although qualitative relationships based on correlations or statistical significance have been found between these characteristics and richness or abundance of some forest species (cf. Table S1), it is still not possible to be precise about the magnitude of the effects of a variation of related index values on biodiversity (Lassauce et al. 2011). As a consequence, a significant statistical disparity in indicator values does not necessarily mean a significant difference in forest species diversity. Studies that focus on the magnitude of the effects (cf. e.g. Barbier et al. 2009), instead of simply testing significant statistical differences among indicator values, are therefore needed if we want to improve indirect forest biodiversity assessment in relation to stand structure.

\section{Conclusion}

Our results bring some insights into the complex issue of ecological forest management. In all, the analyses performed showed that present changes in management practices of heterogeneous European mountain forests are moving towards an improvement of their potential for forest biodiversity conservation. In particular, the expansion of single-tree or group selection silviculture may enhance forest structural diversity at the landscape level provided that other silvicultural practices leading to stand types with complementary structural characteristics are also maintained, for instance coppices with standards or simple coppices. Maintaining uneven proportions of different stand types also appeared to be an important factor in favouring high structural diversity at the forest landscape level. With this case from the Alps, we thus add evidence to support Bunnell and Huggard's (1999) advice aimed at forest managers concerned by biodiversity-related principles: "In particular, be wary of any rule, policy or guideline that prescribes the same thing everywhere".

Acknowledgments The map of forest stand structure was provided by the National Forest Office (NFO), and we thank all the local forest managers who contributed to the field work preparation. Several people assisted in the field, and this research could not have been done without their help. We especially thank Marc Fuhr, Eric Mermin, Gilles Favier, Pascal Tardif, Sophie Labonne, Romain Verger, David Thomasset and Jonathan Charles. Special appreciation goes to Valentine Lafond for her comments that helped us in improving the manuscript as well as Ron Smith from the Centre for Ecology and Hydrology who helped with valuable comments and the editing of the final manuscript. We also thank the anonymous reviewers, the editor and the associate editor for their valuable comments that also strongly helped to improve the manuscript. This research was conducted on the long-term research site Zone Atelier Alpes, a member of LTER France.

Funding This work was financially supported by a graduate student research fellowship to M. Redon from Grenoble University, France, and by funds from the FORGECO project (ANR-09-STRA-02-01).

\section{References}

Angers VA, Messier C, Beaudet M, Leduc A (2005) Comparing composition and structure in old-growth and harvested (selection and diameter-limit cuts) northern hardwood stands in Quebec. For Ecol Manag 217:275-293

Ares A, Shanti B, Puettmann KJ (2009) Understory vegetation response to thinning disturbance of varying complexity in coniferous stands. Appl Veg Sci 12:472-487 
Bagnaresi U, Giannini R, Grassi G, Minotta G, Paffetti D, Pini Prato E et al (2002) Stand structure and biodiversity in mixed, uneven-aged coniferous forests in the eastern Alps. Forestry 75:357-364

Barbier S, Chevalier R, Loussot P, Bergès L, Gosselin F (2009) Improving biodiversity indicators of sustainable forest management: tree genus abundance rather than tree genus richness and dominance for understory vegetation in French lowland oak hornbeam forests. For Ecol Manag 258:S176-S186

Battles JJ, Shlisky AJ, Barrett RH, Heald RC, Allen-Diaz BH (2001) The effects of forest management on plant species diversity in a Sierran conifer forest. For Ecol Manag 146:211-222

Beese WJ, Bryant AA (1999) Effect of alternative silvicultural systems on vegetation and bird communities in coastal montane forests of British Columbia, Canada. For Ecol Manag 115:231-242

Bouget C, Duelli P (2004) The effects of windthrow on forest insect communities: a literature review. Biol Conserv 118:281-299

Bruciamacchie M (2005) Protocole de suivi des espaces naturels protégés. Ministère de l'Ecologie et du Développement Durable.

Bunnell FL, Huggard DJ (1999) Biodiversity across spatial and temporal scales: problems and opportunities. For Ecol Manag 115:113-126

Carey AB (2001) Induced spatial heterogeneity in forest canopies: responses of small mammals. J Wildl Manag 65:1014-1027

Chávez V, Macdonald SE (2010) The influence of canopy patch mosaics on understory plant community composition in boreal mixed wood forest. For Ecol Manag 259:1067-1075

Cordonnier T, Courbaud B, Berger F, Franc A (2008) Permanence of resilience and protection efficiency in mountain Norway spruce forest stands: a simulation study. For Ecol Manag 256:347-354

Decocq G, Aubert M, Dupont F, Alard D, Saguez R, Wattez-Franger A et al (2004) Plant diversity in a managed temperate deciduous forest: understorey response to two silvicultural systems. J Appl Ecol 41: 1065-1079

Di Ciccio TJ, Romano JP (1988) A review of bootstrap confidence intervals. J R Stat Soc B 50:338-354

Fahrig L, Baudry J, Brotons L, Burel FG, Crist TO, Fuller RJ et al (2011) Functional landscape heterogeneity and animal biodiversity in agricultural landscapes. Ecol Lett 14:101-112

Fox J (2002) Bootstrapping regression models. Appendix to an R and SPLUS companion to applied regression. Sage publications

Gauquelin X, Courbaud B (2006) Guide des sylvicultures de montagneAlpes du Nord françaises. Cemagref, CRPF Rhône-Alpes, ONF

Hansen AJ, McComb WC, Vega R, Raphael MG, Hunter M (1995) Bird habitat relationships in natural and managed forests in the West Cascades of Oregon. Ecol Appl 5:555-569

Harrell FE (2001) Regression modeling strategies, with applications to linear models, logistic regression, and survival analysis. Springer, New-York

Haveri BA, Carey AB (2000) Forest management strategy, spatial heterogeneity, and winter birds in Washington. Wildl Soc Bull 28:643652
Holm S (1979) A simple sequentially rejective multiple test procedure. Scand J Stat 6:65-70

Lassauce A, Paillet Y, Jactel H, Bouget C (2011) Deadwood as a surrogate for forest biodiversity: meta-analysis of correlations between deadwood volume and species richness of saproxylic organisms. Ecol Indic 11:1027-1039

Matthews JD (1991) Silvicultural systems. Oxford University Press, New-York

McArdle BH, Anderson MJ (2004) Variance heterogeneity, transformations, and models of species abundance: a cautionary tale. Can J Fish Aquat Sci 61:1294-1302

McElhinny C, Gibbons P, Brack C, Bauhus J (2005) Forest and woodland stand structural complexity: its definition and measurement. For Ecol Manag 218:1-24

McMullin RT, Duinker PN, Richardson DHS, Cameron RP, Hamilton DC, Newmaster SG (2010) Relationships between the structural complexity and lichen community in coniferous forests of southwestern Nova Scotia. For Ecol Manag 260:744-449

MCPFE (2003) Improved pan-European indicators for sustainable forest management. Expert level meeting of the Ministerial Conference on the Protection of Forests in Europe, Vienna.

O’Hara K (2009) Multiaged silviculture in North America. J For Sci 55: $432-436$

Økland B, Bakke A, Hågvar S, Kvamme T (1996) What factors influence the diversity of saproxylic beetles? A multiscaled study from a spruce forest in southern Norway. Biodivers Conserv 5:75-100

Penttilä R, Siitonen J, Kuusinen M (2004) Polypore diversity in managed and old-growth boreal Picea abies forests in southern Finland. Biol Conserv 117:271-283

Poirazidis K, Kati V, Schindler S, Triantakonstantis D, Kalivas D, and Gatzogiannis S (2010) Landscape and biodiversity in Dadia Lefkimi - Soufli Forest National Park. In: Biodiversity, management and conservation. WWF Greece, Athens

Schall P, Ammer C (2013) How to quantify forest management intensity in Central European forests. Eur J For Res 132:379-396

Spies TA, Turner MGI (1999) Dynamic forest mosaics. In: Hunter ML (ed) Maintaining biodiversity in forest ecosystems. Cambridge University Press, Cambridge, pp 335-361

Uotila A, Kouki J (2005) Understorey vegetation in spruce-dominated forests in eastern Finland and Russian Karelia: successional patterns after anthropogenic and natural disturbances. For Ecol Manag 215: 113-137

Vuidot A, Paillet Y, Archaux F, Gosselin F (2011) Influence of the tree characteristics and forest management on tree microhabitats. Biol Conserv 144:441-450

Werner SM, Raffa KF (2000) Effects of forest management practices on the diversity of ground-occurring beetles in mixed northern hardwood forests of the Great Lakes region. For Ecol Manag 139:135155

Willson MF (1974) Avian community organization and habitat structure. Ecology 55:1017-1029 